\title{
Study of symptomatology and presentations of COVID-19 in pregnancy at a tertiary care hospital
}

\author{
Ankita M. Metkari*, Tushar T. Palve
}

Department of Obstetrics and Gynaecology, Grant Government Medical College and Sir JJ Group of Hospitals, Mumbai, Maharashtra, India

Received: 20 August 2020

Revised: 06 October 2020

Accepted: 07 October 2020

*Correspondence:

Dr. Ankita M. Metkari,

E-mail: ankitametkari@gmail.com

Copyright: (C) the author(s), publisher and licensee Medip Academy. This is an open-access article distributed under the terms of the Creative Commons Attribution Non-Commercial License, which permits unrestricted non-commercial use, distribution, and reproduction in any medium, provided the original work is properly cited.

\section{ABSTRACT}

Background: Objectives of this study were to study the incidence of SARS-CoV-19 positivity and the incidence of different signs and symptoms associated with COVID-19 in pregnancy and comparison of the same with studies done in different populations previously.

Methods: In this retrospective study, antepartum and postpartum parameters were integrated into the clinical records and total 205 ANC and PNC SARS-CoV-19 positive patients were evaluated for the signs and symptoms of COVID 19 over 2 months.

Results: In our study, of all patients tested SARS-CoV-19 positive only $14.65 \%$ were symptomatic and rest were incidentally tested positive on admission. Of the symptomatic patients $50 \%$ had breathlessness followed by fever (13.33\%). 92\% patients had mild disease; approximately $8 \%$ had moderate disease and 6 out of 205 patient needed ICU care.

Conclusions: The present study shows that $85.35 \%$ SARS-CoV-19 positive ANC and PNC patients were asymptomatic while only $14.65 \%$ symptomatic with breathlessness being the most common symptom at our institute.

Keywords: SARS-CoV-19 in pregnancy, COVID-19, Symptomatology in pregnancy

\section{INTRODUCTION}

Coronavirus disease 2019 is an emerging disease with a rapid increase in cases and deaths since its first identification in Wuhan, China, in December 2019. Corona virus disease19 (COVID-19) has become a global pandemic with $1,64,94,128$ number of case worldwide while in India the total number of cases have been 2396637 and death due to COVID-19 being 66999 as on 13 August, 2020. ${ }^{1}$ Its unparalleled speed of spread has left us all in a worldwide alarming situation. The causative agent is Severe acute respiratory syndrome Coronavirus 2 (SARS-CoV-2). It's a single stranded RNA enveloped virus causing various degrees of illness ranging from common cold to pneumonia and acute respiratory distress. ${ }^{2}$ Importantly, viral respiratory illnesses, such as influenza, can easily develop during pregnancy, which means pregnant women may be more vulnerable to COVID-19 and require prioritized medical care. Although the risk of infection in pregnant woman is the same as that in general population but previous studies have indicated that SARS during gestation is linked with a high risk of spontaneous miscarriage, preterm birth and intrauterine growth restriction. ${ }^{3}$

As pregnancy is a state of immunosuppression and along with other physiological respiratory and immune changes, pregnant women might show more severe symptoms of COVID-19 infection. To date, studies in pregnant women with COVID-19 have indicated few 
maternal and neonatal complications. ${ }^{4}$ The vertical transmission risk remains uncertain. ${ }^{5}$

The objective of this study was to study the incidence of SARS-CoV-19 positivity among pregnant women getting admitted for obstetric emergency and to study the symptomatology and clinical presentations of COVID-19 in these patients.

\section{METHODS}

This observational study has been conducted in the department of obstetrics and gynecology at Cama and Albless Hospital in Mumbai, spanning over 2 months from 1 May 2020 to 30 June 2020 with a sample size of 205 cases of COVID positive pregnant and postpartum women. Approval of ethical committee was taken.

\section{Inclusion criteria}

All pregnant women admitted at the hospital and testing positive for SARS-CoV-19 by RT-PCR. All postnatal patients who were diagnosed intrapartum or immediate postpartum as COVID positive and transferred to Cama hospital for COVID care.

\section{Exclusion criteria}

All those tested negative for SARS-CoV-19 and gynaecological patients and healthcare workers were excluded out of the study. All patients coming to OPD and Emergency care were first screened for symptoms of COVID-19 and divided into low and high risk of COVID with the help of a screening questionnaire measuring severity of symptoms, history of contact with confirmed or suspected cases of COVID-19 and community exposure. Thorough history was taken to trace contact with COVID patients, any symptoms suggestive of respiratory illness and signs eliciting respiratory compromise. All patients regardless of presence or absence of symptoms COVID-19 oropharyngeal or nasopharyngeal swab were taken and sent for RT- PCR testing. Diagnosis of COVID-19 is mainly based on computed tomography (CT) scans and reverse transcription polymerase chain reaction (RT-PCR). This test is routinely employed for the detection of viruses responsible for respiratory illnesses. ${ }^{6}$ In the RT-PCR technique, viral isolates are used as a primary substrate to perform an assay that identifies a specific virus and its gene sequence. ${ }^{7}$

All data was collected after taking due consent of the patients and their family members after taking ethical Committee approval and Microsoft Office Excel was used for analysis of the data.

\section{RESULTS}

Out of the 205 patients documented 107 were antenatal patients while 98 were postnatal patients transferred for
COVID care. Among the study population, there were 1 spontaneous abortion and 4 ectopic pregnancies. Out of the rest, 17 patients were post-dated on admission, 45 were full term, 27 patients from 32 weeks to 36 weeks and 6 days, 4 patients in the range of 28 to 32 weeks. Second trimester admissions were 4 and 7 in first trimester including abortion and ectopic gestation as mentioned in (Table 1). Out of all 205 patients 76 were nulliparous, and 96 of 107 (92.04\%) had been infected with SARS-CoV-2 in the third trimester.

\section{Table 1: Trimester wise incidence of SARS-CoV-19 positivity.}

\begin{tabular}{|l|l|}
\hline ANC & N \\
\hline Postdated & 17 \\
\hline Full term & 48 \\
\hline 32-37 weeks & 27 \\
\hline 28-32 weeks & 4 \\
\hline Second trimester & 4 \\
\hline First trimester & 2 \\
\hline Ectopic gestation & 4 \\
\hline Abortion & 1 \\
\hline Total & 107 \\
\hline
\end{tabular}

Table 2: Parity and SARS-CoV-19 positivity.

\begin{tabular}{|ll|}
\hline Variables & N $(\%)$ \\
\hline Nulliparous & $76(37.07)$ \\
\hline Parous & $129(62.93)$ \\
\hline
\end{tabular}

Out of all the 205 patients 69 patients were high risk patients with known comorbidities such as hypo/hyperthyroidism, anemia, hypertension in pregnancy, gestational or overt diabetes or a high risk pregnancy. This number is of significance as it was suggested that the severity of infection may depend on the underlying health of the individual patients with preexisting illnesses, such as diabetes and lung disease, as well as the elderly, being more prone to the rapid development of COVID-19. ${ }^{8}$ Overall, $33.66 \%$ had at least 1 coexisting illness; frequently reported illnesses included hypothyroidism, hypertension and anemia (Table 3 ).

It was seen from screening that only 16 of the 107 pregnant women were symptomatic with symptoms such as fever, cough, cold and breathlessness, 91 of 106 $(85.04 \%)$ pregnant women were asymptomatic at admission (Table 4). Most PNC mothers admitted for COVID-19 care were asymptomatic and incidental SARS-CoV-19 positive. Among these patients all had a community exposure, defined as being located within a setting with a known outbreak and only 2 women had direct contact with a known infected person.

A total of 91 of 107 pregnant women $(92 \%)$ had no to mild disease, and $9(8 \%)$ had moderate disease (hypoxemia), although of the 205 patients 6 patients were 
needed to be shifted to the ICU after persistent drop in saturation even on $\mathrm{O} 2$ support for breathlessness.

Table 3: Distribution of associated comorbidity/high risk factors among the study population.

\begin{tabular}{|ll|}
\hline $\begin{array}{l}\text { Associated comorbidity/ } \\
\text { high risk factor }\end{array}$ & N $(\%)$ \\
\hline Thyroid abnormality & $15(21.74)$ \\
\hline Hypertensive disorders in pregnancy & $20(28.98)$ \\
\hline Anemia & $12(17.39)$ \\
\hline Diabetes in pregnancy & $2(2.9)$ \\
\hline APH & $3(4.35)$ \\
\hline Twin gestation & $3(4.35)$ \\
\hline IUFD & $1(1.45)$ \\
\hline Tuberculosis & $3(4.35)$ \\
\hline Bronchial asthma & $2(2.9)$ \\
\hline Others & $8(11.59)$ \\
\hline
\end{tabular}

Table 4: Presenting signs and symptoms associated with COVID-19 among the study population.

\begin{tabular}{|ll|}
\hline Variables & $\mathbf{N}(\%)$ \\
\hline Signs & \\
\hline Asymptomatic & $175(85.35)$ \\
\hline symptomatic & $30(14.65)$ \\
\hline Symptoms & \\
\hline Fever & $4(13.33)$ \\
\hline Cough & $3(10)$ \\
\hline Cold & $3(10)$ \\
\hline Breathlessness & $15(50)$ \\
\hline Fatigue & $1(3.33)$ \\
\hline Diarrhoea & $0(0)$ \\
\hline Headache & $2(6.66)$ \\
\hline Chest tightness & $2(6.66)$ \\
\hline
\end{tabular}

A total of 179 of 205 patients $(87.31 \%)$ had delivered during the study period and had 180 births (1 set of twins). Out of these patients, $31.84 \%$ underwent a cesarean section; of which 2 were preterm LSCS. In none of the cases LSCS was performed because of concern about the effects of Covid-19 on the pregnancy and all were due to an obstetric indication or elective LSCS. 3 patients delivered vaginally after cesarean section. A total of 16 deliveries $(8.9 \%)$ were premature. Exploratory laparotomy was performed in all 4 patients diagnosed with ectopic gestation.

\section{DISCUSSION}

A similar study was done in Wuhan, China from 8 December, 2019 to 20 March, 2020, where 118 pregnant women were studied with the median age of women being 30 years. ${ }^{8,9}$ Out of the study population $52 \%$ were nulliparous as compared to our study in which there was a disparity between the parity with $62.93 \%$ patients being parous. As per the study in Wuhan SARS-CoV-2 positivity was seen in majority in the third trimester which constituted $64 \%$ of the study population similar to our study where it was $60.74 \%$ (65 out of 107). High detection rate of SARS-CoV-19 in the third trimester could be attributed to increased incidence of testing in this group as the patients reached near term. As per the study at Wuhan, 95\% patients had symptoms with fever and cough being the most common symptoms (75\% and $73 \%$ respectively) which was also consistent with the findings of meta analysis review by Matar et al while only $5 \%$ were asymptomatic and were screened only because of exposure to persons with confirmed or suspected COVID-19. ${ }^{1,8}$ Contrary to the above in our study it was seen that $85.35 \%$ patients tested positive for SARS-CoV-19 positive by RT-PCR were asymptomatic while only $14.63 \%$ were symptomatic in which breathlessness was the most common symptom $(50 \%)$ followed by fever $(13.33 \%)$. This contradiction in symptomatology could be attributed to generalized testing of all pregnant women reaching term regardless of presence or absence of symptoms. The findings here are suggestive of a high rate of SARS-CoV-19 positivity in asymptomatic pregnant women who can be a source in the community if not detected at the earliest. Hence, routine screening of all pregnant women is emphasized based on the above found results. In our study it was seen that 6 out of 205 patients (2.93\%) eventually needed ICU admission while the rest were discharged with an uneventful course in the hospital.

\section{CONCLUSION}

In this study done at a tertiary care centre in Mumbai, it was seen that of the 205 patients only $14.65 \%$ patients were symptomatic at presentation or developed symptoms during their course in the hospital. Hence it can be safely said that approximately $85 \%$ of SARSCoV-19 positive patients did not develop disease manifestations and were infected as a result of community exposure and could be potential silent sources for transmission of the causative agent. The above results hence highlight the need of proper screening and testing for SARS-CoV-19 regardless of presence or absence of signs and symptoms in all pregnant women as followed at our institution.

\section{Funding: No funding sources}

Conflict of interest: None declared

Ethical approval: The study was approved by the Institutional Ethics Committee

\section{REFERENCES}

1. Culp WC. Coronavirus disease 2019: in-home isolation room construction. A A Pract. 2020;14(6):e01218.

2. Gorbalenya AE, Baker SC, Baric RS. Severe acute respiratory syndrome-related coronavirus: the species and its viruses- a statement of the Coronavirus study group. Int J Sci Health Res. 2020;5(2):140. 
3. Wong SF, Chow KM, Leung TN, Ng WF, Ng TK, Shek CC, et al. Pregnancy and perinatal outcomes of women with severe acute respiratory syndrome. Am J Obstet Gynecol. 2004;191(1):292-7.

4. Zhu H, Wang L, Fang C, Peng S, Zhang L, Chang G, et al. Clinical analysis of 10 neonates born to mothers with 2019-nCoV pneumonia. Transl Pediatr. 2020;9(1):51-60.

5. Chen H, Guo J, Wang C, Luo F, Yu X, Zhang W, et al. Clinical characteristics and intrauterine vertical transmission potential of COVID-19 infection in nine pregnant women: a retrospective review of medical records. Lancet. 2020;395(10226):809-15.

6. Corman VM, Landt O, Kaiser M, Molenkamp R, Meijer A, Chu DK, et al. Detection of 2019 novel coronavirus (2019-nCoV) by real-time RT-PCR. Euro Surveill. 2020;25(3):2000045.

7. Emery SL, Erdman DD, Bowen MD, Newton BR, Winchell JM, Meyer RF, et al. Real-time reverse tran- scription-polymerase chain reaction assay for SARS-associated coronavirus. Emerg Infect Dis. 2004;10:311-6.

8. Centers for disease control and prevention, Coronavirus disease 2019 (COVID-19). Available at: https ://www.cdc.gov/coron aviru s/2019-ncov/sympt oms-testi ng/sympt oms.html. Accessed on 14 March 2020.

9. Fu L, Wang B, Yuan T, Chen X, Ao Y, Fitzpatrick $\mathrm{T}$, et al. Clinical characteristics of coronavirus disease 2019 (COVID-19) in China: A systematic review and meta-analysis. J Infect. 2020;80(6):65665.

Cite this article as: Metkari AM, Palve TT. Study of symptomatology and presentations of COVID-19 in pregnancy at a tertiary care hospital. Int J Reprod Contracept Obstet Gynecol 2020;9:4410-3. 